\title{
Aspectos da construção da imagem do índio na narrativa Quarup, de Antônio Callado
}

\section{Aspects of the native's building in the narrative Quarup, Antônio Callado}

\author{
Jorge Alves SANTANA* \\ $U F G$ \\ Layssa Gabriela Almeida e SILVA** \\ Anhanguera Educacional/GO \\ Larissa Cardoso BELTRÃO ${ }^{* * *}$ \\ UFG/UEG
}

A nação preenche o vazio deixado pelo desenraizamento de comunidades e parentescos, transformando esta perda na linguagem da metáfora (BHABHA, 1998).

Nossas sociedades são compostas não de um, mas de muitos povos. Suas origens não são únicas, mas diversas. Aqueles aos quais originalmente a terra pertencia, em geral, pereceram há muito tempo - dizimados pelo trabalho pesado e a doença. A terra não pode ser sagrada", pois foi "violada” - não vazia, mas esvaziada (HALL, 2003).

- Não se assuste, Manuel. Eu agora viro qualquer coisa (CALLADO, 1977).

Resumo: Neste artigo temos como objetivo evidenciar aspectos do heterogêneo processo de construção da identidade cultural do índio contemporâneo brasileiro de forma a ressaltar a partir da narrativa Quarup, de Antônio Callado (1977), a relação entre literatura e estudos culturais. Tais reflexões são embasadas predominantemente pelos estudos de Maria Elisa Cevasco (2003), Stuart Hall (2003, 2006) e Homi Bhabha (1998).

Palavras-chave: Estudos Culturais. Quarup. Índio.

\begin{abstract}
In this article we attempt to highlight aspects of the heterogeneous process of building the cultural identity of the contemporaneous Brazilian indian in order to emphasize from narrative Quarup, Antonio Callado (1977), the relationship between literature and cultural studies. Such reflections here are based predominantly by Maria Elisa Cevasco studies (2003), Stuart Hall (2003, 2006) and Homi Bhabha (1998).
\end{abstract}

Keywords: Cultural Studies. Quarup. Indian.
* Doutor em Letras. jorgeufg@bol.com.br

** Mestre em Letras e Linguística. layssagabriela@ hotmail.com.br

*** Mestre em Letras e Linguística. larissabeltrao@bol. com.br 
Este artigo reflete sobre a possibilidade de a narrativa literária, vista como fato cultural vinculado à constituição social, contribuir para a produção de sentidos e valores que performam aspectos daquilo que seria a cartografia da nacionalidade brasileira. Em tal cartografia pluralizada e provisória, acompanharemos algumas características identitárias de determinados povos indígenas, particularmente aqueles do Parque Indígena do Xingu que são representados na narrativa Quarup, de Antônio Callado, sob a perspectiva dos Estudos Culturais. Essa perspectiva nos permitirá deslocar nossa atenção do estudo puramente intrínseco do que seria a construção literária, para o relevante diálogo com o pensamento cultural que se direciona para questões de cunho social e histórico. Assim, o fenômeno artístico tende a ser percebido de modo tanto estético, uma de suas dimensões de base, quanto no modo de intervenção analítica e processual na realidade pragmática na qual obra literária, autor, mensagem e recepção, está historicizada.

Com vistas a promover a relação entre literatura e estudos culturais, um dos nossos campos metodológicos principais, fundamentamos nossa pesquisa em Cevasco (2003), Bhabha (1998), Hall (2006), entre outros.

\section{Das construções cujos fundamentos são velados}

De acordo com Bhabha (1998, p. 304), a base grupal dos novos movimentos sociais apresenta, em sua estrutura, uma objetividade social que também pode ser parcializada e relativizada quanto ao intento da construção de quadros complexos, supostamente completos e fixados da realidade. Para ele, na pós-modernidade, ou na contemporaneidade, como prefere Giorgio Agamben (2009), surge entre os agrupamentos sóciopolíticos, formados por variados segmentos minoritários, uma espécie de “pseudo-dialética” que, por sua vez, seria fruto da solidariedade existente entre tais grupos. Assim, o autor aponta para a necessidade de os estudos que tratam de fatos sociais, usualmente múltiplos e complexos, usarem perspectivas e materiais de análise que contemplem a diversidade que defende o surgimento de heterogêneos traços culturais que conformam a realidade estratificada.

Assim, a tentativa de apenas mapear diferentes posicionamentos de identidades, sejam eles de etnia, de raça, de nacionalidade, bem como de outras institucionalidades, com seus conjuntos de valores e prática marcados de modo implícito ou explícito, solicita um posicionamento verdadeiramente dialético. Posicionamento dialético este que de fato respeite a diversidade constitutiva dos fenômenos e circunstâncias, sem as costumeiras conservadoras ancoragens de denominadores comuns que apenas viabilizam a construção de um campo mediano em que as possíveis diferenças são amenizadas ou apagadas. 
Nessa perspectiva, colocamos em cena a obra Quarup, de Antônio Callado, publicada em 1967, que recebe este nome por ter como um dos temas centrais o ritual indígena de celebração dos heróis mortos que tanto resgata a tradição do povo que executa tal prática quanto o mobiliza também para enfrentar existencialidades novas que naturalmente a compleição sociocultural acarreta. Trata-se de uma narrativa moldada por focalização onisciente que predominantemente seria neutra, porém apresentando também pontuações judicativas sobre o universo ficcional construído e sua rede de contatos com os dados factuais que atualiza de modo estético.

Predomina no texto a questão indígena brasileira. Este segmento social é colocado em foco também para, de forma subjacente, se pensar a constituição contemporânea do complexo fenômeno que seria a brasilidade, contexto antropologicamente consensual tido como o receptáculo de identidades variadas e em constante natureza processual.

Ao lado dos intricados aspectos identitários das variadas etnias indígenas representadas por Antônio Callado, também pensamos nas multiformes dimensões que conformam a ideia de nação que subjaz a essa narrativa romanesca. Nação como unidade substancial feita pela junção de povos, práticas e valores que são conformados em relatos oficiais que marcam e asseguram a tradição coletiva unificada e unificadora. Sobre essa criação social que perpassa, por vezes, uma longa e controlada cronotopia, o pensador Stuart Hall (2006), baseado em estudos dos demais pensadores e ativistas da Esquerda Inglesa, pontua o fenômeno da nacionalidade como um exercício coletivo de imaginação capaz de criar supostas condições que definiriam a comunidade política como coesa, limitada e soberana. As nações, e, por analogia, outros processos e produtos do campo da identificação, tais como a etnia, a raça, a identidade pessoal, são realidades imaginadas. Na situação particular da nação, temos que se trata de uma realidade imaginada porque as sucessivas gerações de habitantes dos mais variados grupos étnicos não são diretamente coautores das tradições que, por vezes, inconscientemente são obrigados a atualizar em seus cotidianos. Coesa, porque as instituições como o governo, a educação, a religião e os códigos de leis padronizam as possibilidades de ação para a população geograficamente demarcada. Limitada, pois se estrutura pela lei tácita da separação arbitrária entre o alheio e o próprio. Soberana, porque unida pelo ímpeto bélico de defender o que seria a propriedade coletiva perante outras comunidades.

Dessa forma, o elemento humano que é o indígena - elemento humano tão complexo e heterogêneo como qualquer outro elemento humano - parece entrar na equação de um romance que trataria especificamente de sua produção cultural mantenedora de sua sociedade, parece entrar de modo forçado no painel que representaria essa unidade niveladora das diferenças étnicas e, consequentemente, políticas. 
Stuart Hall segue as reflexões, que iniciamos acima, sobre a questão quando assegura que:

No mundo moderno, as culturas nacionais em que nascemos se constituem em uma das principais fontes de identidade cultural. Ao nos definirmos, algumas vezes dizemos que somos ingleses ou indianos ou jamaicanos. Obviamente, ao fazer isso estamos falando de forma metafórica. Essas identidades não estão literalmente impressas em nossos genes. Entretanto, nós efetivamente pensamos nelas como se fossem parte de nossa natureza essencial (HALL, 2006, p. 47).

Nação, nacionalidade, nacionalismo perfazem, pois, aquele campo semântico sedimentado por sentidos do que seria a cultura nacional. Como não são situações e condições naturais, mas historicizadas por simbolização até mesmo criptografadas, Hall (2006) aponta para o caráter metafórico de tal construção. Metáfora naturalizada de modo impositivo, pois o sujeito "nacionalizado" não tem o poder de escolher fazer parte ou não do processo que o encerra em um produto de modo inflexível.

Sobre esse caráter metafórico do produto estabelecido de modo pragmático, também acompanhamos Homi Bhabha (1998) que, em seu instigante livro $O$ local da cultura, também nos esclarece:

Se, em nossa teoria itinerante, estamos conscientes da metaforicidade dos povos de comunidades imaginadas - migrantes ou metropolitanos - então vemos que o espaço do povo-nação moderno nunca é simplesmente horizontal. Seu movimento metafórico reque um tipo de duplicidade de escrita, uma temporalidade de representação que se move entre formações culturais e processos sociais sem uma lógica causal centrada (BHABHA, 1998, p. 201).

O caráter da metáfora funciona como um dispositivo que pode dinamizar nossa visão sobre esses poderosos construtos que modelam nossas perspectivas sobre o seríamos, sobre como nossos ambientes sócio-político-culturais são e sobre nossas possibilidades de sujeitos agentes nesses territórios das identidades.

\section{Da contribuição criada pelos Estudos Culturais}

Apesar de as metodologias de análise do campo dos Estudos Literários ainda gerarem certa resistência em espaços acadêmicos e afins, pensamos que se trata de um instrumental que enriquece as perspectivas de índole intrínseca. Assim, consideramos útil pontuarmos o tema para refletirmos com mais vagar sobre as formações discursivas literárias e suas performances de fatos sociais e culturais que, além de representar a complexidade da realidade pragmática, com toda sua ancoragem estética, também potencializam sua força de intervenção na realidade da qual faz parte. 
A relação entre estudos culturais e estudos literários já é bastante perceptível. Há estudiosos que acreditam que os estudos de cultura nada mais são do que uma extensão dos estudos literários (CEVASCO, 2003, p. 138); outros por sua vez, postulam que os estudos culturais são mais abrangentes, uma vez que incluem e abrangem os estudos literários (CULLER, 1999, p. 49) e há aqueles que temem que os estudos culturais, como disciplina, poderiam desestabilizar o valor fechado da literatura, ou melhor, do que seria a literatura considerada como arte culta. Talvez esse temor de destruição da alta literatura tenha se dado em grande medida pelo fato de um dos impulsos dos estudos culturais terem sido o de lutar para que "a cultura exclusivista começasse a fazer parte de uma cultura em comum, onde os significados e valores fossem construídos por todos e não por uns poucos privilegiados” (CEVASCO, 2003, p. 139).

Essa virada no conceito de cultura se deu a partir da década de 1960. Aboliu-se o uso de Cultura, com letra maiúscula, e passou-se a adotar culturas, com um "s” no final, já que nesta era pós-moderna, os estudiosos buscavam lutar pelo reconhecimento das diferenças e pela supressão do universalismo (CEVASCO, 2003, p.24).

Ao fazer um levantamento histórico para verificar quando se deu o surgimento dos estudos culturais, percebemos que sua origem pode ser evidenciada na publicação de três grandes obras: The making of the English Working Class (1963), de Edward P. Thompson; Culture and Society (1958), de Raymond Williams; e The uses of Literacy (1957), de Richard Hoggart, referências que ainda acompanhamos no informativo estudo de Maria Elisa Cevasco (2003, p. 13). Quanto às universidades, cabe destacar o Centro de Estudos Culturais Contemporâneos da Universidade de Birmingham, pioneira no programa de pós-graduação em estudos culturais. No Brasil acredita-se que o congresso anual da Abralic em 1998, com o tema "Literatura comparada = estudos culturais?" foi um intenso e instigante momento de desdobramentos epistêmicos que representou a chegada e difusão dos estudos culturais na academia e grupos de pesquisa brasileiros. Cevasco (2003, p. 174) ressalta ainda três características dos estudos culturais que nos auxiliam a distingui-lo da literatura comparada: seu projeto político, suas ligações com a realidade social e sua diferença na prática cultural.

Exposto, de modo sumário, a relação entre os estudos literários e os estudos culturais e, consequentemente a importância de tal metodologia para esse nosso estudo, retornaremos à análise na narração de Quarup, com o intuito de verificar as estratégias representativas, conscientes e inconscientes, que criam a imagem do índio brasileiro, ou de modo mais adequado, a imagem das várias etnias indígenas brasileiras que foram dispostas de modo arbitrário no experimento antropo-social é o Parque Indígena do Xingu. 


\section{Do índio, vislumbrou-se a sombra}

Dado o panorama teórico com o qual nos movemos, temos que a narrativa romanesca de Antônio Callado representa, predominantemente, um dos maiores empreendimentos antropo-sociológicos já construídos pelo que seria a nação brasileira. Tal contexto é a projeção e execução do Parque Indígena do Xingu, outrora Parque Nacional Indígena do Xingu, no início dos anos sessenta do século passado. A temporalidade abrange os anos de 1954 a 1964. Período marcado por grandes desdobramentos da política industrial e expansionista do governo getulista e de seus desdobramentos que culminarão no Golpe Militar de 64.

O enunciado de Quarup, por mais que se esforce no contexto pontual da criação do Parque Nacional do Xingu, desdobra-se na exploração de núcleos accionais que são importantes, mas que, talvez, não teriam ligação direta com o núcleo central indicado de modo referencial pelo título da obra. No entanto, quando de trata de agenciamentos discursivos literários, somos inclinados a ler o título, e o corpo textual que dele emana, no registro da alegoria que parece tratar a questão indígena como um teatro do que ocorre no âmbito nacional envolvendo questões sociais, políticas e culturais que são imbricadas no maior projeto de agrupamento indígena não natural que o mundo já vira.

Assim, questões como as da consolidação do parque industrial brasileiro, das relações trabalhistas regidas por legislação que começam a funcionar, das relações conflituosas entre campo e cidade, das consequências desumanas do êxodo rural, do papel da igreja de cunho socialista em uma sociedade acentuadamente desigual, das lutas armadas no campo e na cidade, da transferência da capital federal do Rio de Janeiro para Brasília, do apogeu da famosa "marcha para o oeste", iniciada pragmaticamente no primeiro governo getulista. A lista de tópicos importantes é grande. E nisso talvez se dilua a questão maior para a qual o título do romance aponta, criando grandes expectativas no leitor que talvez deseja compreender como a literatura trata do indígena na contemporaneidade de uma nação que transforma suas estruturas de modo vigoroso.

Mesmo assim, o índio está na narrativa. Não um índio insulado em uma etnia exclusiva, mas o índio pluralizado. De acordo com Bruna Franquetto (2011) e Carmem Junqueira et al. (2005), o empreendimento xinguano juntou forçosamente cerca de quatorze etnias diferentes que cobrem todos os quatro troncos linguísticos indígenas brasileiros que são os troncos caribe, aruaque, tupi e macro-jê. Por volta de 1961, aviões do Exército Brasileiro campeavam povos indígenas nas mais diversas regiões do Brasil com o objetivo oficial de preservar suas identidades em uma região única. Assim, ex abrupto, grupos inteiros foram transportados para a primeira demarcação indígena brasileira e obrigados a encontrar uma 
unidade multiétnica que lhes asseguraria a preservação diante do contato da exploradora e voraz sociedade do homem branco.

Não entraremos na polêmica antropológica que tal empreendimento gerou mundo afora. No entanto, vale o registro de que a complexa ação foi, e continua sendo, elogiada por muitos organismos internacionais, além de catapultar seus principais atores com ação direta e indireta, os irmãos Villas-Bôas, O marechal Rondon, Darcy Ribeiro, Noel Nutesl, Café Filho entre outros, para o panteão dos heróis da nação. Ironicamente, nenhum índio parece ter entrado para esse panteão exclusivista e arbitrário formado pela etnia com predominantes traços europeizados.

Do ponto de vista narrativo, esse intricado e polêmico - pelas iconoclastias do tratamento temático - romance que é Quarup está dividido em sete partes, as quais tecem a teia que dão vida à engenhosa e instigante textualização. Durante o desenvolvimento de suas células de conflito, é possível entrar em contato aspectos do processo de formação do índio contemporâneo, tanto pelo olhar do outro, o homem branco, quanto pelo dos demais membros da tribo que, apesar de serem focados com pouca atenção, estão em contato direto com o grupo que organiza o parque xinguano.

A predominância de focalização narrativa desse romance, como mencionamos, é do campo da onisciência, aspecto que cria aquela ambiência do olhar oficial que captura a situação sob condição unificada, coesa e plenificada. Também temos, em Quarup, a presença de um narrador onisciente multisseletivo que, a partir de seu discurso, aproxima-se dos interiores de algumas personagens, criando, assim, uma espécie de construção de sentidos dialógicos. No entanto, sob o aspecto quantitativo e também no qualitativo, predomina a perspectiva de conjunto unificado que é percebida por uma enunciação centralizadora.

O romance está estruturado em torno de Nando, um padre do interior de Pernambuco que recebe por missão catequizar os índios do Posto Capitão Vasconcelos, região que viria a ser o Parque Indígena do Xingu. Assim, exercendo a condição de protagonista, já no início da obra, ele é apresentado a partir de um conflito interior de cunho moral, que nasce de sua educação religiosa conservadora: Nando quer ir para o Xingu com o objetivo de envolver-se no portentoso projeto sócio-político, no entanto teme não resistir à visão das índias nuas.

Na primeira parte, denominada Ossuário, Nando sai do mosteiro pernambucano, mais especificamente de um Ossuário, entra em contato com a Liga dos Camponeses, passa a relacionar-se com um casal de protestantes ingleses, sendo só depois de ter sua vida sexual iniciada, que abandona o temor da visão das índias nuas. Parte para o Rio de Janeiro, onde vai encontrar o grupo multitarefa responsável pela instalação do parque indígena e toma o avião que o levará para o Xingu. O segundo capítulo recebe o nome de Éter. Já no Rio de Janeiro, Nando, em companhia dos 
funcionários do ministro Gouveia, mais uma vez é tentado a evidenciar e experimentar o lado carnal e sensual do ser humano ao fazer uso excessivo de éter. Além disso, nos dias que antecedem sua partida, torna-se amante de Vanda, sobrinha e secretaria de Ramiro, chefe de gabinete do ministério.

A terceira parte é denominada $A$ maçã. Ao chegar ao Posto Capitão Vasconcelos - Xingu, o padre Nando é recebido por Fontoura, que por meio de uma brincadeira reconstrói o mito de Adão e Eva. E lá, nos dias que se seguem, dedica-se a conhecer os membros da comunidade. Entre tais índios, destacamos o índio Anta, um dos poucos índios que assumirão papel de destaque ao longo da trama. É a partir dele que teremos as noções de construção da identidade do índio contemporâneo. Ainda nessa parte, a rádio local anuncia uma possível chegada do presidente Jânio Quadros para vistoria e inauguração do parque. Assim, as várias tribos, de etnias diferentes, iniciam os preparativos para o ritual do Quarup, ritual esse que ainda não estava padronizado para todo o parque, como ocorre atualmente.

O capítulo seguinte recebe nome de A orquídea, no qual há um salto temporal visível. Ainda no Xingu, Nando volta a Recife onde tem sua vida religiosa abalada por dois acontecimentos: a morte de seu mentor espiritual D. Anselmo e o desligamento do padre Hosana. Agora, imerso em uma vida desregrada, ele recebe da ordem um pedido de afastamento e retorna ao Xingu. Nesse retorno, ele já é apresentado como tendo um comportamento despojado, convive com os índios de igual para igual, já não era padre, apenas homem disposto a assumir os riscos de encontros interculturais sem a preocupação de misturar-se com aqueles que antes ele considerava portadores de diferenças intransponíveis. Já nessa nova condição ele é surpreendido pela chegada de Francisca, que foi para a o Xingu como integrante da expedição Centro Geográfico do Brasil.

Na quinta parte, A palavra, de volta a Pernambuco, Francisca, com o intuito de dar seguimento ao trabalho realizado por Levindo, o líder dos movimentos campesinos, vai para o campo onde desenvolve o trabalho de alfabetização dos camponeses do Movimento Cultura Popular. Nando emociona-se ao ver que, durante o processo de alfabetização, Francisca falava também sobre a Declaração dos Direitos Humanos e sobre a Constituição brasileira. Nando morando agora numa casinha de praia que herdara de sua família, se torna um aliado de Januário, outro líder dos camponeses, até ser preso durante o Golpe Militar de 1964. Também ambientado em Recife, no sexto capítulo, A praia, depois de libertar-se da prisão, Nando recolhe-se na casa da praia. Ainda preso a Francisca, ele resolve celebrar uma espécie de Quarup em homenagem a Levindo. Mas no dia da festa ele é torturado pela marcha dos populares. Socorrido por Manuel Tropeiro, seu companheiro de luta, e por Hosana, foi levado da praia.

O desfecho da narrativa é evidenciado na sétima e última parte, em um capítulo denominado $O$ mundo de Francisca. Demorou algum tempo até que Nando conseguisse se recuperar da tortura que havia sofrido dos 
aparelhos repressores do estado. Após ter perdido a visão de um dos olhos e depois da luta por conseguir sair da casa de praia onde estava, Nando decide partir para o sertão na companhia de Manuel Tropeiro e passa agora a assumir uma outra identidade, a de Levindo, o líder comunitário que transforma-se em totem ao redor do qual o protagonista consolida a montagem de sua identidade libertária e libertadora.

Escrito na década de 60, o romance Quarup tem como pano de fundo, como começamos a explorar anteriormente, um Brasil marcado por fortes tensões político-sociais. O país vivia, na época, um momento de posição entre diferentes princípios e ideologias. O movimento que suscitava a Reforma Agrária ganhava força e os movimentos populares eram ativados em grande parte da extensão territorial do Brasil, como é caso do Movimento de Cultura Popular, em Recife. Tanto as camadas excêntricas das zonas urbanas quanto aquelas rurais se mobilizavam, para tornar a nação brasileira justa quanto, principalmente, à distribuição de renda.

A criação da Empresa Brasileira de Telecomunicações diminuía as distâncias, e a televisão brasileira, apesar de enfrentar momentos de contradição, também começava a firmar-se como meio comunicação de massa ao lado das transmissões radiofônicas de grande abrangência. A literatura, por sua vez, continuava a influenciar fortemente a mídia em formação e consolidação do país, de modo que grandes nomes do universo literário passaram desenvolver funções nas redações jornalísticas.

Nesse contexto em que percebemos formações enunciativas literárias ligadas a formações discursivas do campo político, antropológico, social e cultural, pensamos que a questão da alegorização do real, uma das funções da literatura, transborda a natureza das metáforas - que talvez pudesse ser aquela da utopia preservacionista e redentora dos contatos interculturais do parque indígena - que pareciam apontar para a Expedição Quarup e fundação do parque, mas que no fundo indicaria mais uma espécie de formação sentimental e política do coração e da mente do ex-padre Nando. Um padre intelectual que, inspirado por Francisca e Levindo, foi um dos membros ativos do grupo que efetiva a tal expedição e implantação do experimento, bem como a luta pela solução dos conflitos entre camponeses e grandes proprietários de terra. A partir de suas experiências, Nando tece o universo de relações no qual seu processo de construção de identidade vai lhe conferindo, mesmo que de modo fragmentado, a sensação especular de integridade pessoal que também atuará sobre uma imagem íntegra do tecido social sobre o qual montará a intencionalidade de intervenção.

Como o momento histórico, Nando constrói-se utopicamente entre Pernambuco, Rio de Janeiro e Parque Xingu, mostrando-se, o tempo todo, dividido entre as sensações e luxúrias carne e a contensão e ascese do espírito, a miséria do campo brasileiro e a dissolução existencial e accional cotidiana dos grandes centros urbanos. 
Teríamos, pois, nessa perspectiva, uma tentativa de representação do panorama da nação unificada - índios e não índios - que parte dos fragmentos temporariamente individuais das subjetividades que se movem por situações diversificadas. A partir do desejo intimista do padre Nando de unir as pontas do Brasil, colocando-se em contato, de modo um tanto enviesado, identidades culturais indígenas com um grande número de manifestações político-culturais de conflitos dos variados segmentos sociais, que movimentavam as intensas crises pelas quais a nação passava na década de 60 .

\section{Do intrínseco que ancora a perspectiva dialógica}

Quarup é um romance que por diversos momentos estabelece comunicação evidente com a realidade factual. Segundo Mires Bender (2010, p. 3), esta comunicação com a realidade serviu ainda para reproduzir um momento histórico, que apesar da censura imposta na época, permanece registrado na literatura nacional de expressão próxima dos textos documentais. Gisele Dias (2007, p. 2), no entanto, chama a atenção para o fato de que apesar de existir diálogo intrínseco entre Quarup e o contexto sócio-histórico, cabe ao leitor perceber que a obra literária não deve ser vista como uma reprodução direta ou espelhamento de tal período.

Além da ditatura militar, época em que o livro foi escrito, é preciso levar em consideração o modo como os índios e sua cultura são expostos na obra. Cristiane de Assis Portela (2009) em um trabalho no qual busca promover a reflexão sobre a história indígena brasileira, afirma que:

A história indígena no Brasil foi marcada pela imposição de uma unidade nacional que excluía a diversidade e "lembrava", sob diferentes formas de violência, que índios deveriam deixar de ser índios. Na contemporaneidade, as formas de violência persistem, a despeito dos avanços jurídicos conquistados pelos movimentos indígenas nas últimas décadas do século XX. Porém, no âmbito do imaginário nacional, há inúmeras ideias estereotipadas que foram consolidadas historicamente (PORTELA, 2009, p. 151).

Em Quarup é possível percebermos muitas destas histórias estereotipadas que foram sendo construídas sobre os indígenas. E é por esta razão, que, entre os inúmeros temas presentes na obra, enfatizamos as imagens construídas sobre os povos indígenas aldeados de modo massivo no Xingu.

Os excertos 1 e 2 extraídos da obra revelam que os índios em Quarup são vistos por diversos momentos como indivíduos canibais e selvagens:

[1]

- O juruna! O Juruna! - disse Lauro.

- Morto- disse Olavo. - Jubé. Assassinado. Dois índios. Caíram em cima dele feito um raio. 
- Que índios? - disse Vilaverde. - Txukarramãe?

- Não - disse Olavo. - Cren-acárore (CALLADO, 1977, p. 289-290).

[2]

- Olha aqui, eu quero dizer uma coisa a vocês. Um punhado de brancos, com fuzis e balas, imobilizados por índios semimortos é coisa que nunca se viu. (...)

- Faz assim graça, à custa da nossa vida - disse Lauro - porque não tem coragem de ser chefe, de assumir a responsabilidade dos seus atos. É como o cria dele, Vilaverde. São os bonzinhos. Ganham o dinheiro do Estado para bancarem apóstolo entre índios. Mas para me matarem no meio dessa vadiagem não! Débeis mentais, ignorantes! É ridículo, ouviram bem, ridículo em qualquer parte do mundo sacrificar homens civilizados e cultos a selvagens (CALLADO, 1977, p. 293-294).

Além de serem vistos como canibais e selvagens, há um momento no quarto capítulo do livro, A orquídea, em que Lauro, em meio à expedição para achar o centro geográfico do Brasil, instante belo e ao mesmo tempo com tons de tragédia nacional, alerta padre Nando a fazer uso de uma vara para manter os índios que eles haviam encontrado durante o percurso. Tal atitude de Lauro nos faz crer que os indígenas são para ele seres animalizados e, consequentemente inferiores ao homem branco:

[3]

A índia com que ele falava metia os dedos de puro osso nos bolsos de Ramiro em busca de alguma comida.

- Não deixem que te toquem! - disse Lauro.

- Lauro tinha na mão uma vara comprida com a qual matinha os índios à distância (CALLADO, 1977, p. 292).

Ainda em meio à expedição, o grupo se depara com cartazes de Sônia, uma moça branca que havia desaparecido com o índio Anta (aquele que mencionamos anteriores ao destacá-lo como exemplo raro de índio que atua com certa importância na economia da narrativa), e descobrem que um grupo de brasileiros juntamente com italianos e franceses estão gravando um filme sobre a biografia da moça. Ainda na mata, eles encontram com um grupo indígena que se recusa a dar informações sobre a Sônia e o possível raptor indígena, sem antes receber algo em troca:

[4]

(...) Movidos talvez pelo açodamento de Ramiro os txukarramãe não o levaram logo à cabana da mulher branca. Ramiro teve de dar como presentes 
a eles até as duas camisas engomadas que ainda guardava” (CALLADO, 1977, p. 281).

Nota-se no excerto 4 que os índios são vistos pelos integrantes da expedição como indivíduos espertos e interesseiros, completamente inseridos na economia de mercado da sociedade do homem branco, que se pauta pela exploração do trabalho alheio e pela voracidade de acumular o lucro de forma privada. Nota-se ainda que os índios são retratados como seres capazes de perpetuar ações inusitadas e horríveis, como atesta o fragmento:

[5]

Lauro sombrio advertia:

- Não se esqueçam por favor que estamos em terra virgem, entrando em contato com um grupo de índios inteiramente desconhecidos. Todos os horrores são possíveis. Não esqueçam que padres jesuítas, nos tempos de descobrimento, descreveram monstros encontrados até nas matas litorâneas. Vamos subir o rio até ao Jarina, vamos deixar de novidades (CALLADO, 1977, p. 286-287).

Viver como os índios, na ótica do grupo multitarefa criado por Antônio Callado, implicava colocar a vida em sérios contextos de enfrentamentos, perigos e de crise, uma vez que eles eram vistos pelos brancos como seres diferentes, exóticos e de difícil assimilação intercultural. O momento em que Francisca conversa com Nando sobre o sumiço de Sônia evidencia tal afirmação:

[6]

- Você pensou que fosse Sônia, meu bem? - disse Nando.

- Ah, que impressão terrível, Nando. Tolice minha, é o escuro da maloca. Mas pensei por um momento que a vida selvagem, ou os sofrimentos não sei, tinham transformado ela. Ainda sinto um arrepio, sabe? Como estará Sônia, a verdadeira Sônia? O que acontece se a gente viver durante anos essa vida deles?

- Eu duvido que dure muito tempo, Francisca (CALLADO, 1977, p. 282).

Estas citações já mencionadas nos levam a perceber que o índio contemporâneo de Antônio Callado se assemelha e, ao mesmo tempo, se distingue daquele índio do Romantismo de, por exemplo, um José de Alencar e do Modernismo, por exemplo, alegorizado por Mário de Andrade. O índio contemporâneo deixa de ocupar o posto de herói nacional que se espelha nos ideais comportamentais de culturas eurocêntricas para atingir o lugar do selvagem a ser salvo de sua própria ignorância e da sanha exploradora do homem branco. 


\section{Das considerações finais}

A metodologia analítica dos Estudos Culturais nos auxiliou a configurar possíveis interpretações uma obra literária no diálogo com fatos sociais e culturais. Assim, refletimos sobre construções de noções como dispositivos produtores de identidades que criam/imaginam fenômenos como a etnia e a nação. Tais fenômenos nos são dados como realidades naturais, daquelas que os sujeitos, de modo recorrente, não teriam capacidade de compreensão completa e de ação transformadora.

No campo intrínseco dos agenciamentos enunciativos literários, presentes em Quarup, de Antônio Callado, percebemos como a estratégia das metáforas que constroem o campo alegórico podem alterar o tema que ocuparia papel de destaque na narrativa. Assim, o ritual do Quarup, ação mantenedora e difusora da tradição de certa etnia indígena xinguana, secundariza-se perante a força de atuação das personagens não índias.

A ideia da nação coesa, unificada e soberana permanece em um território que beira os projetos utópicos. Porém, tal noção pode ser percebida em sua constituição talvez mais verdadeira quando traça as linhas fragmentadas e provisórias da cartografia da nação, do Brasil que se quer conhecedor dos múltiplos e heterogêneos estratos humanos. Vale, nessa fase conclusiva, recordarmos da linha de força do pensamento de Stuart Hall:

As identidades nacionais não subordinam todas as outras formas de diferença e não estão livres do jogo de poder, de divisões e contradições internas, de lealdades e de diferenças sobrepostas. Assim, quando vamos discutir se as identidades nacionais estão sendo deslocadas, devemos ter em mente a forma pela qual as culturas nacionais contribuem para "costurar” as diferenças numa única identidade (HALL, 2006. p. 65).

\section{Referências}

AGAMBEN, Giorgio. O que é o contemporâneo e outros ensaios. Tradução de Vinícius Icastro Honesko. Chapecó: Argos, 2009.

BENDER, Mires Batista. “Quarup: uma alegoria do Brasil”. Tabuleiro de Letras, Bahia, número especial, p. 1-22, 2010.

BHABHA, Homi. O local da cultura. Tradução de Myriam Ávila, Eliana Lourenço Reis, Gláucia Renate Gonçalves. Belo Horizonte: UFMG, 1998.

CALLADO, Antônio. Quarup. Rio de Janeiro: Civilização Brasileira, 1977.

CEVASCO, Maria Elisa. Dez lições sobre estudos culturais. São Paulo: Boitempo Editorial, 2003. 
CULLER, Jonathan. Teoria Literária: uma introdução. Tradução de Sandra Vasconcelos. São Paulo: Beca Produções Culturais Ltda., 1999.

DIAS, Gisélia Rodrigues. "Estupefação e o esmaecimento do projeto utópico na ficção de 70: Quarup”. Ícone- Revista de Letras, São Luís de Montes Belos, v. 1, p. 140-153, dez. 2007.

FRANCHETTO, Bruna (org.). Alto Xingu: Uma sociedade multilíngue. Rio de Janeiro: Museu do Índio/Funai, 2011.

HALL, Stuart. Identidades culturais na Pós-modernidade. Trad. Tomaz T. da Silva e Guacira Louro. 11 ed. Rio de Janeiro: DP\&A Ed. 2006.

Da Diáspora: Identidades e Mediações Culturais. Liv Sovik (org); Tradução de Adelaine La Guardia Resende. Belo Horizonte: Editora UFMG; Brasília: Representação da Unesco no Brasil, 2003.

JUNQUEIRA, Carmen; BARUZZI, Roberto G. (org.). Parque Indígena do Xingu: Saúde, cultura e história. São Paulo: Terra Virgem Editora, 2005.

PORTELA, Cristiane de Assis. "Por uma história mais antropológica: indígenas na contemporaneidade”. Sociedade e Cultura, Goiânia, v. 12, n. 1, p. 151-160, jan./jun. 2009.

Data de submissão: 30/04/2014

Data de aprovação: 21/07/2014 